\title{
Corrigendum: Dissecting the Contingent Interactions of Protein Complexes with the Optimized Yeast Cytosine Deaminase Protein-Fragment Complementation Assay
}

Po Hien Ear, Jacqueline Kowarzyk, and Stephen W. Michnick

When this protocol was first published, the concentrations for the reagents in the recipe entitled "Amino Acid Mix (10×)" were expressed as $\mathrm{g} / \mathrm{mL}$, but they should have been expressed as $\mathrm{g} / \mathrm{L}$. The authors apologize for this error. The HTML version of the recipe (doi: 10.1101/pdb.rec090308) has been corrected, as has the current PDF version of the protocol. A corrected version of the recipe is also included below.

\section{Amino Acid Mix (10x)}

Amino acid or nucleobase Concentration $(10 \times)$

Adenine sulfate

$0.4 \mathrm{~g} / \mathrm{L}$

Uracil

$0.2 \mathrm{~g} / \mathrm{L}$

L-Tryptophan

$0.4 \mathrm{~g} / \mathrm{L}$

L-Histidine hydrochloride

$0.2 \mathrm{~g} / \mathrm{L}$

L-Arginine hydrochloride

$0.2 \mathrm{~g} / \mathrm{L}$

L-Tyrosine

$0.3 \mathrm{~g} / \mathrm{L}$

L-Leucine

$0.6 \mathrm{~g} / \mathrm{L}$

L-Lysine hydrochloride

$0.3 \mathrm{~g} / \mathrm{L}$

L-Phenylalanine

$0.5 \mathrm{~g} / \mathrm{L}$

L-Glutamic acid

$1.0 \mathrm{~g} / \mathrm{L}$

L-Asparagine

$1.0 \mathrm{~g} / \mathrm{L}$

L-Valine

$1.5 \mathrm{~g} / \mathrm{L}$

L-Threonine

$2.0 \mathrm{~g} / \mathrm{L}$

L-Serine

$3.75 \mathrm{~g} / \mathrm{L}$

L-Methionine

$0.2 \mathrm{~g} / \mathrm{L}$

Dissolve the amino acids from the list above (except those to be excluded from any dropout media) in distilled $\mathrm{H}_{2} \mathrm{O}$. Filter-sterilize, store at $4^{\circ} \mathrm{C}$, and protect from light. 
Corrigendum: Dissecting the Contingent Interactions of Protein Complexes with the Optimized Yeast Cytosine Deaminase Protein-Fragment Complementation Assay

Po Hien Ear, Jacqueline Kowarzyk and Stephen W. Michnick

Cold Spring Harb Protoc; doi: 10.1101/pdb.corr107814

\begin{aligned} & $\begin{array}{r}\text { Email Alerting } \\ \text { Service }\end{array}$ Receive free email alerts when new articles cite this article - click here. \\ & \hline $\begin{array}{c}\text { Subject } \\ \text { Categories }\end{array}$ Browse articles on similar topics from Cold Spring Harbor Protocols. \\ & \hline\end{aligned}

